requires the cooperation of the subject, as in this instance.

In this investigation subjects with one or more low swept fractions, or a long time constant compared with the performance of the control group, have been selected for comparison with the clinical and radiological findings. The division between an "abnormal" and a "normal" performance was set at twice the standard deviation from the mean performance for the control group, so that about one observation in 40 in a sample from the control group population would be expected, without allowing for individual age differences, to fall below the lower limit for the swept fraction, or above the upper limit for the time constant.

A single low swept fraction or a long time constant could also be due to an extraneous influence during the test, such as a diversion of the subject's attention, inhalation of saliva, or a desire to cough. Two low swept fractions and in addition a long time constant in the same subject are unlikely to be due to such a cause. Of the time constants recorded for 21 subjects in Tables 5 and 6, 17 were greater than the mean plus three times the standard deviation. Only about one subject in 200 from the control group would be expected to fall outside these limits.

Tables 5 and 6 show that the subjects who performed "abnormally" on all the tests showed clinical evidence of emphysema. Not all the subjects with low results in one or two tests showed clinical evidence of respiratory disease, and there were three subjects diagnosed clinically as having emphysema who performed within the limits described on all the tests.

Difficulties involved in the purely clinical diagnosis of emphysema have been discussed by Fletcher (1952) and in the radiological diagnosis of emphysema by Knott and Christie (1951). The assessment of the ventilatory function of the lung taken in conjunction with other findings may be of considerable value in arriving at a diagnosis. It is believed that the methods described in this paper provide a more sensitive index of ventilatory impairment than those hitherto used.

\section{Summary}

Vital capacity, maximum ventilatory capacity at 30 and 70 R.P.M., and expiratory fast vital capacity records have been obtained from groups of workers exposed to cadmium fume in two factories and from control groups with similar age distributions. From this data, swept fractions (at the respiratory rates investigated) and time constants of the expiratory fast vital capacity curves have been obtained.

Measurements of the swept fractions and of the time constants of the expiratory fast vital capacity curves have proved useful in differentiating between the control and the exposed groups.

Standards of normality based on the performance of the control group have been laid down, and individual performances outside the $5 \%$ confidence limits have been compared with the clinical and radiological findings.

The significance of the swept fraction and the time constant, and the measure of agreement with the clinical and radiological findings have been discussed.

I wish to thank Professor J. L. D'Silva for his guidance during this investigation, and also Dr. P. Armitage from the Statistical Research Unit of the Medical Research Council for help with the statistical aspects of this paper.

\section{REFERENCES}

Bernstein, L., D'Silva, J. L., and Mendel, D. (1952). Thorax, 7, 255. -, and Kazantzis, G. (1954). Ibid., 9, 326.

Bonnell, J. A. (1955). British Journal of Industrial Medicine, 12, 181. D'Silva, J. L., Freeland, D. E., and Kazantzis, G. (1953). Thorax, 8,303 . 8, 303.

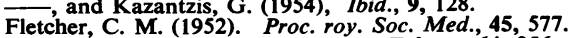

Gaensler, E. A. (1951). Amer. Rev. Tuberc., 64, 256.

Knott, J. M. S., and Christie, R. V. (1951). Lancet, 1, 881.

\title{
PART II : THE ESTIMATION OF THE TOTAL LUNG VOLUME, ITS SUBDIVISIONS, AND THE MIXING COEFFICIENT
}

BY

\section{R. ST. J. BUXTON}

\begin{abstract}
Method
The apparatus used, which in principle employed a closed circuit helium technique with a katharometer, was a modification of that described by Bates and Christie (1950). The side circuit carbon dioxide absorber
\end{abstract}

was omitted, and crushed ice was placed in the spirometer jacket 20 minutes before the start of the experiment. This reduced the rise in temperature in the spirometer. The subject, who was seated in an upright chair, was instructed to breathe normally. He inhaled pure oxygen from a Douglas bag for seven minutes and expired into 
the atmosphere so that the nitrogen of his functional residual air was replaced by oxygen. At the end of a normal expiration he was connected to the spirometer circuit of 4 litres capacity and containing about 10\% helium in oxygen. The gas was circulating at the rate of 50 to 60 litres a minute but the flow through the katharometer was only 0.75 litre per minute.

After a latent period of five to 15 seconds the galvanometer needle started to move, the time lag depending on the katharometer response and the respiratory rate of the subject. The movement was followed by a tracking device as described by Bates and Christie (1950). When the needle ceased to move, showing that mixing was complete, the helium concentration was read. At least two vital capacities were then recorded and the volumes calculated for $37^{\circ} \mathrm{C}$. and saturated with water vapour.

From the above data, the total lung volume and its subdivisions were calculated. The mixing efficiency was calculated and scaled up by $100 / 80$ in the manner described by Bates and Christie (1950).

\section{Experimental Subjects}

Those workers directly exposed to cadmium fumes were studied together with a control group drawn from the brass and iron foundries in the same factory, which was called factory B by Bonnell (1955). The selection of the control group has been discussed by Bonnell (1955). At the time of the clinical examination appointments were made for these respiratory function tests so that more often than not they took place on a different day from the clinical examination. The observer did not know at the time of the test from which group the subject was drawn. One test was made on each individual. In the " exposed" group 37 men out of 42 were studied, five failing to attend, and 36 out of 44 in the control series, eight defaulting.

The ages of the exposed and control groups ranged from 23 to 65 (mean 41.9 years) and 18 to 65 (mean 40.9 years) respectively. Of the men exposed to cadmium fumes, 13 (average age 49.5 years) had been exposed for more than 10 years (cadmium group with a long exposure), and 24 (average age 37.8 years) for less than 10 years (cadmium group with a short exposure).

\section{Results}

Subdivisions of the Total Lung Volume.-Table 1 shows the results obtained and also the probability that the observed differences between the various pairs of means would be exceeded by chance. It will be seen that the mean total lung volume in the three groups (columns 2, 3, and 4) was not significantly different. The mean vital capacity of the subjects in the cadmium group with a long exposure (column 3) was significantly less than of those in the control group (column 2) while the value for the cadmium group with a short exposure (column 4) differed little from the control group. The mean functional residual air was similar in the three groups (columns 2, 3, and 4), but the mean residual air, and the residual air expressed as a percentage of the total lung volume, were significantly greater in the group of men exposed to cadmium for more than 10 years than in the control series (columns 3 and 2).

It has been noted above that there was a considerable difference between the mean ages for the control group and the cadmium group with a long exposure. It was, therefore, necessary to study the relationship between age and the various subdivisions of the lung volume before ascribing the significant differences to other factors.

Total Lung Volume and Age.-There was no regression of significance $(P>0.7)$ of total lung volume on age so that the values recorded in Table 1 for the total lung volume are directly comparable.

TABLE 1

MEAN VALUES FOR SUBDIVISIONS OF TOTAL LUNG VOLUME OF WORKERS EXPOSED TO CADMIUM FUME AND CONTROL SUBJECTS

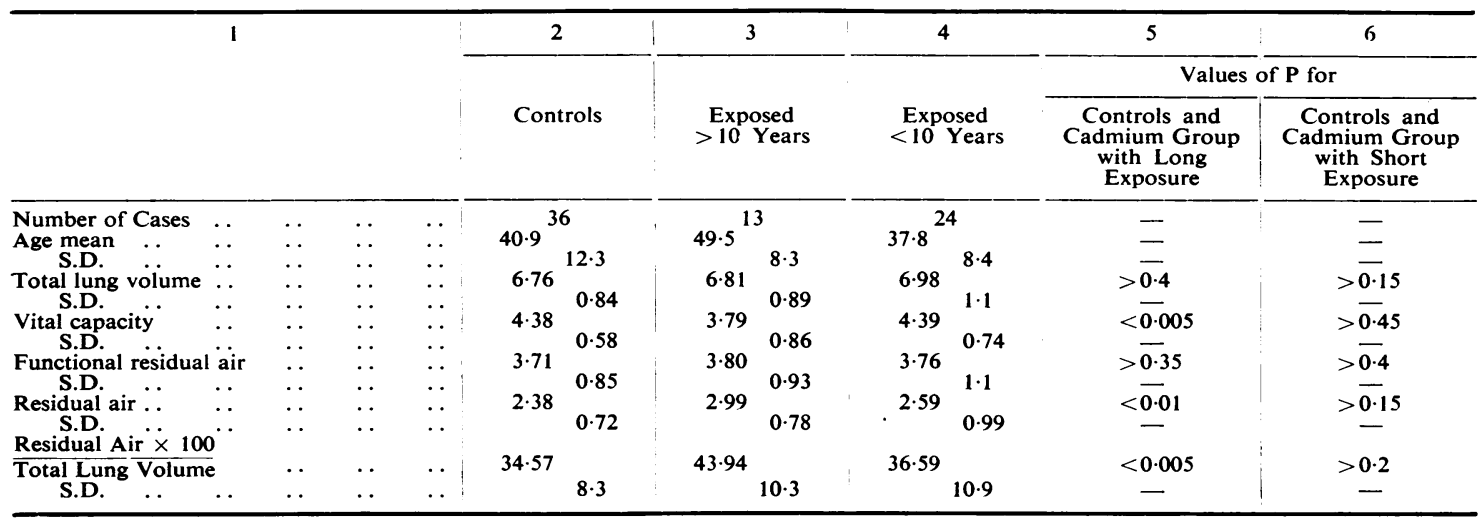


Vital Capacity and Age.-In the control group the vital capacity tends to diminish with increasing age, and the relationship is significant $(P<0.01)$. If parallel lines are fitted to the control group and the cadmium group with long exposure, the difference in position of the two lines does not quite reach the $5 \%$ level ( $P=0.06$ on a one-sided test). Here and at corresponding points in the analysis of the other tests, a one-sided test of significance is employed since exposure to cadmium could hardly be expected to improve respiratory function. If, however, regression lines are fitted separately to the two groups, they are found to differ significantly in their slope $(P=0.01)$, the exposed group having the larger negative regression coefficient. This is due mainly to a number of men at the upper end of the age range who had especially low vital capacities. It may therefore be concluded that for the higher ages at least some factor other than age was responsible for the decrease in vital capacity, and, as the results from the cadmium group with a short exposure did not demonstrate such a difference, the greater length of exposure to cadmium may well be a factor in its production.

Functional Residual Air and Age.-Since there was no significant regression $(P>0 \cdot 1)$ in the values of functional residual air and age, their further manipulation in Table 1 is not required. The results for the cadmium group with long and short exposure and the control group remain not significantly different.

Residual Air and Age. - The volume of the residual air tends to increase with increased age, the slope of the line for the control group being significant $(0.01<\mathbf{P}<0.05)$. Lines fitted to the control group and to the cadmium group with a long exposure did not differ significantly in slope $(0 \cdot 1<P<0 \cdot 2)$. The difference in position, however, of the parallel lines is on the border of significance $(P=0.05)$.

Residual Air as a Percentage of Total Lung Volume and Age.-The residual air expressed as a percentage of total lung volume tends to increase with age. The difference in slope of lines fitted separately to the control group and the cadmium group with a long exposure does not quite reach the $\mathbf{P}=\mathbf{0 . 0 5}$ level of significance. The slope of the lines is, however, highly significant $(P<0.01)$, and their positions differ significantly $(P=0.01)$, the mean values in the exposed group being higher at any given age. This difference is not shown by the cadmium group having a short exposure so that the length of exposure to cadmium may be a causative factor.
Mixing Efficiency.-The mixing coefficients were calculated by the method of Bates and Christie (1950). The mean for the control group $(49.3 \%$, S.D. 10.0) and that for the cadmium group with a long exposure (53.1\%, S.D. 15.8) showed a difference which was barely significant $(P>0.05)$. The cadmium group with a short exposure had a mean of $49.5 \%$ (S.D. 16.7) which did not differ significantly $(P>0.4)$ from the control figure. There was. no significant regression of the mixing coefficient on age $(P>0.5)$ in the control group.

Assessment of Individual Workers. - Consideration of individuals in a group is statistically less easy than making an appraisal of the group as a whole. The control group in this investigation was selected in a manner which was considered to allow a fairer assessment of the cadmium workers in relation to the general population of similar age than if any arbitrary standard of fitness had been employed. After making allowance for age, the limit of normality has been taken as the sum or difference of twice the standard deviation and the mean of the control group, or, where applicable, twice the standard deviation from regression. This means that one in $\mathbf{4 0}$ of the control observations can be expected to fall outside the limits set. Table 2 shows only those subjects in the control series and in the groups exposed to cadmium whose results for the total lung volume, its subdivisions, the relative percentage of residual air to total lung. volume, or for the mixing coefficient, fall outside the limit.

It will be observed that of 36 subjects in the control group, 33 were within the limits set in every test. Nos. B14 and B34 were each outside this range in one test only, an observation which can well be ascribed to random error. Subject B30, aged 25 years, had a past history of a spontaneous pneumothorax without other evidence of chest disease, an occurrence which could account for the abnormal figures obtained in tests 2 and 4 .

Of the 13 individuals in the cadmium group with a long exposure, nine gave results within the limits adopted in all six tests. No. B5's performance in test 4 may well have been influenced by random errors. But three out of 13 had low figures in test 2 , and three out of 13 high values in test 5 which is significant as each of the subjects B31, B4, and B1 gave abnormal results in both tests.

In the cadmium group exposed for a shorter period, 18 of 24 subjects gave results within the range adopted as normal in each of the six tests. Subject B38 suffered from bronchial asthma of some years' duration and abnormal findings would be expected, so that he need be considered no further 
TABLE 2

RESULTS ADJUSTED FOR AGE IN CASES WITH ABNORMAL FINDINGS

\begin{tabular}{|c|c|c|c|c|c|c|c|}
\hline \multirow[b]{2}{*}{ Group } & \multirow{2}{*}{$\begin{array}{l}\text { Case } \\
\text { Number }\end{array}$} & 1 & 2 & 3 & 4 & 5 & 6 \\
\hline & & $\begin{array}{l}\text { Total Lung } \\
\text { Volume }\end{array}$ & $\begin{array}{l}\text { Vital } \\
\text { Capacity }\end{array}$ & $\begin{array}{l}\text { Functional } \\
\text { Residual Air }\end{array}$ & $\begin{array}{l}\text { Residual } \\
\text { Air }\end{array}$ & $\frac{\text { Residual Air } \times 100}{\text { Total Lung Volume }}$ & $\begin{array}{l}\text { Mixing } \\
\text { Coefficient }\end{array}$ \\
\hline Control & $\begin{array}{l}\text { B30 } \\
\text { B14 } \\
\text { B34 }\end{array}$ & $\bar{z}$ & $\begin{array}{c}\text { Low } \\
- \\
-\end{array}$ & $\overline{\text { High }}$ & $\begin{array}{l}\text { High } \\
-\end{array}$ & $\overline{-}$ & $\overline{\text { Low }}$ \\
\hline $\begin{array}{l}\text { Cadmium with } \\
\text { long exposure }\end{array}$ & $\begin{array}{l}\text { B31 } \\
\text { B4 } \\
\text { B5 } \\
\text { B1 }\end{array}$ & $\underline{-}$ & $\begin{array}{l}\text { Low } \\
\text { Low } \\
\overline{\text { Low }}\end{array}$ & $\begin{array}{l}E \\
-\end{array}$ & $\overline{\text { High }}$ & $\begin{array}{l}\text { High } \\
\text { High } \\
\overline{\text { High }}\end{array}$ & E \\
\hline $\begin{array}{l}\text { Cadmium with } \\
\text { short exposure }\end{array}$ & $\begin{array}{l}\text { B6 } \\
\text { B33 } \\
\text { B35 } \\
\text { B36 } \\
\text { B37 } \\
\text { B38 }\end{array}$ & $\begin{array}{l}\overline{\text { High }} \\
\overline{\text { High }} \\
\overline{\text { High }}\end{array}$ & $\begin{array}{l}\frac{\text { Low }}{\text { Low }} \\
\frac{\text { Low }}{-}\end{array}$ & $\begin{array}{l}\overline{\text { High }} \\
\overline{-} \\
- \\
-\end{array}$ & $\begin{array}{l}\text { High } \\
\text { High } \\
\overline{\text { High }} \\
\overline{\text { High }}\end{array}$ & $\begin{array}{c}\text { High } \\
\text { High } \\
- \\
\overline{-} \\
\text { High }\end{array}$ & $\begin{array}{l}\overline{\text { Low }} \\
\overline{-} \\
-\end{array}$ \\
\hline
\end{tabular}

" High" signifies a value greater, and "low" less, than the limit set, namely, twice the standard deviation from the control mean, or, where applicable, twice the standard deviation from regression.

in this paper. Nos. B35 and B37 had low vital capacity figures which can be ascribed to chance factors operating. Subject B36 performed poorly in tests 1 and 4, No. B6 in tests 2, 4, and 5, while No. B33 had a normal figure for his vital capacity only.

The tests listed in Table 2 are not completely independent of one another in a statistical sense, and the degree of their interdependence cannot be assessed. It would therefore be difficult to calculate the probability of a given subject producing abnormal results in more than one test by operation of the laws of chance.

\section{Comment}

In the present investigation no single subject had abnormal figures for the total lung volume and all four of its subdivisions when compared with the control group. The residual air expressed as a percentage of the total lung volume was high in some cases (Table 2). This has been suggested by Hurtado and Boller (1933), Friberg (1950), and Bates and Christie (1950) as a reliable aid in the diagnosis of emphysema. As yet there is no precise information as to the factors on which the volume of the residual air, the functional residual air, the vital capacity, or the total lung volume depend. In any series of normal subjects the size of this fraction, of the volume of the residual air, and of the total lung volume vary widely so that there is no theoretical reason for supporting the assumption that a value for this fraction of over $42 \%$ (Bates and Christie, 1950) or over 35\% (Hurtado and Boller, 1933) is evidence of emphysema. Until the factors on which the total lung volume and its subdivisions depend are known, the only sound method of assessing results is on a statistical basis. This applies particularly to this study since the nature of the alteration in function of the lungs which may occur with exposure to cadmium fume has not been fully worked out.

In comparing these results with those of Kazantzis in Part I it should be noted that the control group in this paper contained 36 men all of whom featured in his series. But in the group exposed to cadmium the five defaulters all belonged to the group exposed for less than 10 years, while Kazantzis had one defaulter in each exposed group. The difference in vital capacity figures in the two papers could not be explained by the difference in the number of subjects involved, although Kazantzis' deductions are drawn from the results of the exposed group as a whole, while the conclusions in this paper are based on the figures obtained from the 13 men exposed to cadmium for more than 10 years. Further, his subjects were examined in the standing position, and, in this study, sitting in a chair. It may be therefore that posture played a part in producing the discrepancies, and different characteristics of the apparatus may also be involved. This would only be the case if any disability were accentuated by these factors.

The measure of agreement between the clinical assessment and the performance in the various tests of respiratory function may be seen in Table 3 . Kazantzis' three tests are the swept fractions at $\mathbf{3 0}$ and 70 respirations per minute and the time constant for the expiratory fast vital capacity curve. The author's six points are the total lung volume, the vital capacity, the functional residual air, the residual air, the residual air expressed as a percentage of total lung volume, and the mixing coefficient. In neither series of tests are the variables independent of one another. Of the workers exposed to cadmium 
TABLE 3

CORRELATION OF ABNORMAL RESULTS

\begin{tabular}{|c|c|c|c|c|c|}
\hline \multirow[t]{2}{*}{ Group } & \multirow[t]{2}{*}{$\begin{array}{c}\text { Case } \\
\text { Number }\end{array}$} & \multirow[t]{2}{*}{$\begin{array}{c}\text { Clinical } \\
\text { Findings }\end{array}$} & \multirow{2}{*}{$\begin{array}{l}\text { Radio- } \\
\text { logical } \\
\text { Findings }\end{array}$} & \multicolumn{2}{|c|}{$\begin{array}{c}\text { Results of } \\
\text { Respiratory } \\
\text { Function Tests }\end{array}$} \\
\hline & & & & Kazantzis & Buxton \\
\hline Control & $\begin{array}{l}\text { B30 } \\
\text { B14 } \\
\text { B34 } \\
\text { B13 } \\
\text { B32 } \\
\text { B12 } \\
\text { B15 } \\
\text { B39 }\end{array}$ & $\begin{array}{l}E \\
E \\
E \\
E\end{array}$ & $\begin{array}{l}\bar{E} \\
\bar{E} \\
\bar{E}\end{array}$ & $\begin{array}{l}\overline{1 / 3} \\
\overline{1 / 3} \\
\overline{3 / 3} \\
1 / 3 \\
-\end{array}$ & $\begin{array}{l}2 / 6 \\
1 / 6 \\
1 / 6 \\
- \\
- \\
-\end{array}$ \\
\hline $\begin{array}{l}\text { Cadmium } \\
\text { with long } \\
\text { exposure }\end{array}$ & $\begin{array}{l}\text { B31 } \\
\text { B4 } \\
\text { B5 } \\
\text { B1 } \\
\text { B11 } \\
\text { B2 }\end{array}$ & $\begin{array}{l}\overline{\mathbf{E}} \\
\mathbf{E} \\
\mathbf{E} \\
- \\
-\end{array}$ & $\begin{array}{l}\bar{E} \\
\bar{E} \\
\bar{E}\end{array}$ & $\begin{array}{l}\overline{3 / 3} \\
1 / 3 \\
3 / 3 \\
1 / 3 \\
2 / 3\end{array}$ & $\begin{array}{l}2 / 6 \\
2 / 6 \\
1 / 6 \\
2 / 6 \\
- \\
-\end{array}$ \\
\hline $\begin{array}{l}\text { Cadmium } \\
\text { with short } \\
\text { exposure }\end{array}$ & $\begin{array}{l}\text { B6 } \\
\text { B35 } \\
\text { B33 } \\
\text { B36 } \\
\text { B37 } \\
\text { B38 } \\
\text { B3 }\end{array}$ & $\begin{array}{l}E \\
E \\
E \\
E \\
E\end{array}$ & $\begin{array}{l}\text { E } \\
\bar{Z} \\
\bar{E}\end{array}$ & $\begin{array}{l}\frac{3 / 3}{E} \\
\bar{E} \\
\overline{3 / 3}\end{array}$ & $\begin{array}{l}3 / 6 \\
1 / 6 \\
5 / 6 \\
2 / 6 \\
1 / 6 \\
3 / 6 \\
-\end{array}$ \\
\hline
\end{tabular}

$E=$ emphysema. Kazantzis' results are obtained from page 32.

fume in factory B, five were diagnosed clinically as having emphysema. Four of these (B1, B4, B3, and B6) were found to be abnormal in each of Kazantzis' three tests, and three had an increased residual air : total lung volume ratio, while subject B5 had a residual air figure outside the limit set. The other abnormal figures for the residual air expressed as a percentage of the total lung volume were obtained from subjects B31 and B33 who were clinically normal and produced normal values in the tests of ventilatory function. The effect of choosing a population which was unselected on the grounds of health may affect the standards adopted in the ventilatory tests and the gas distribution procedures differently. Further it would be expected that where the pathological condition existed in a less severe degree this might be detected in one set of tests but not necessarily in all the tests. In consequence it is not unexpected that the results of the respiratory function tests correlated satisfactorily in the severely affected cases with the clinical and radiological assessment but poorly where the condition was less marked.

\section{Summary}

This survey was composed of 36 control subjects and 37 men who had been exposed to cadmium fume.

Estimation of the total lung volume, its subdivisions, and of the mixing coefficient was made in each case.

The 13 workers whose exposure to cadmium was of more than 10 years' duration performed less well when compared as a group than the control series.

The difference between the 24 workers whose exposure to cadmium was less than 10 years and the control group was not significant.

In each of the two exposed groups three subjects produced results which were abnormal and unlikely to be chance findings.

It was concluded that these tests of respiratory function showed that the group exposed to cadmium for more than 10 years differed significantly from the control group, that certain individual workers gave abnormal figures, and that these differences could not be ascribed to chance.

It gives me great pleasure to acknowledge the help of Professor J. L. D'Silva. My thanks are also due to Dr. P. Armitage for statistical advice and to Miss Audrey Murden for technical assistance.

\section{REFERENCES}

Bates, D. V., and Christie, R. V. (1950). Clin. Sci., 9, 17. Bonnell, J. A. (1955). British Journal of Industrial Medicine, 12, 181. Friberg, L. (1950). Acta med. scand., Suppl. 240.

Hurtado, A., and Boller, C. (1933). J. clin. Invest., 12, 793. 